\section{Bathless Dissolution: Validation of System Performance}

Gerald Brinker and Beth Goldstein

Distek, Inc.

Brunswick, N7

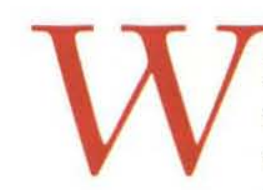

ThA's growing emphasis on the need to establish that systems are suitable for their intended uses, pharmaceutical companies are increasingly demanding that their vendors provide them with an ever-expanding level of proof of performance. In the laboratory area, some companies have gone so far as to demand that equipment suppliers provide complete validation protocols

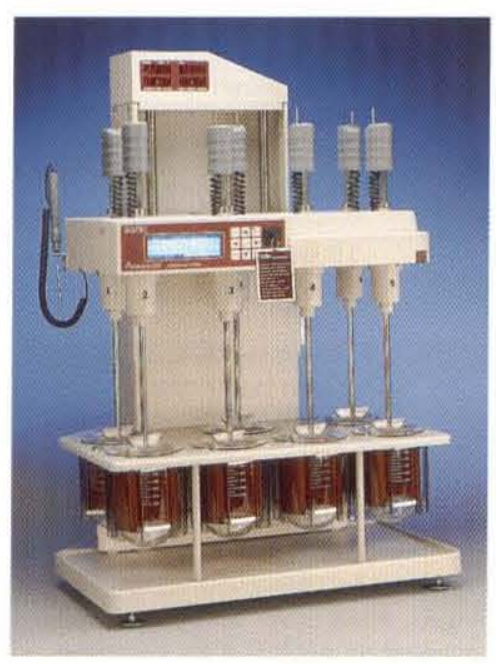

For many years the USP paddle method has proved to be a robust test for determining the dissolution rates of solid dosage forms. This article focuses on validating the performance of a new, innovative batbless dissolution system. encompassing the system installation, operation, and, in some cases, performance qualification. Most vendors, understanding that FDA holds the end user responsible for on-site validation, have tended to limit their support to providing guidance validation protocols as a line item option available to the user. Typically, vendors will also charge for additional support in developing the end user's validation protocol. In some cases, when the user has purchased direct vendor validation support, vendors have provided their personnel to perform the user's approved validation protocol, with the user's quality unit acting as the review and approval agent.

This article discusses the verification of system component conformity to specifications as well as key highlights from the validation of the performance of the Premiere 5100 bathless dissolution system (Distek, Inc., North Brunswick, NJ). These studies were performed to establish that the system is fit for use in performing the United States Pharmacopeia (USP) suitability test (1) specifically and for USP-based dissolution studies in general. The system is a seven-vessel, directly heated unit fitted with paddles. Before these studies began, the system was installed and its installation and operation were verified as conforming to the manufacturer's specifications. All measurements were made using calibrated NIST-traceable measurement instruments, except that vessel hemisphericity was verified using VesselChek, an external metal template (Distek). The system's level was confirmed using the built-in circular spirit level and an auxiliary carpenter's level. The system was installed on a bench in the firm's demonstration room with a printer attached to record sets of time, temperature, and stirring speed (rpm) data. The nominal temperature in this area was approximately $22^{\circ} \mathrm{C}$. In keeping with vendor recommendations, the system was not placed in the discharge stream of any heating, ventilation, and air conditioning (HVAC) register.

The general approach to validate system performance was to:

- verify the physical dimensions of the key components (vessels, paddles, and vessel covers)

- establish that the installed components met their alignment and, in the case of the paddles, their rotational specifications

- confirm the accuracy of the system's reference temperature probe on which the seven temperature-sensing shafts' accuracy is based and perform a calibration check on the system

- determine that the system's heating met its heating time windows

- establish that the temperature of the medium in the vessels conformed to its set point; was uniform within the stirred medium; met its expected between- and withinvessel temperature variation tolerances; remained within its short- and long-term drift specifications; and was not significantly affected when, contrary to USP's directions, the covers were removed from the vessels.

In all cases, the plan was to establish that the results obtained conformed to Distek's established specifications (see Tables I and II).

\section{THE VALIDATION PLAN}

Based on the general approach outlined in the preceding paragraph, a formal validation plan was drafted. After 


\section{Bathless Dissolution. ...ent.}

Table I: USP's and Distek's specifications for key physital components.

\begin{tabular}{|c|c|c|}
\hline Item & USP Requirements & Vendor Requirements \\
\hline \multicolumn{3}{|l|}{ Vessel Specifications } \\
\hline Material of construction & $\begin{array}{l}\text { Glass or other transparent } \\
\text { material that is nonreactive }\end{array}$ & Borosilicate glass \\
\hline Key markings & Not specified & $\begin{array}{l}\text { Serial number, volume lines, and a } \\
\text { locating mark on its outer surface }\end{array}$ \\
\hline Vessel shape & $\begin{array}{l}\text { Top-flanged cylinder with a } \\
\text { hemispherical bottom }\end{array}$ & $\begin{array}{l}\text { Top-flanged (with flat flange underside) } \\
\text { cylinder with a hemispherical bottom }\end{array}$ \\
\hline 1- $L$ vessel's outside height & $160-210 \mathrm{~mm}$ & $164.0-172.0 \mathrm{~mm}$ \\
\hline 1- $L$ vessel's outside diameter (o.d.) & Not specified & $105.0-109.0 \mathrm{~mm}$ \\
\hline 1- $L$ vessel's inside diameter (i.d.) & $98.106 \mathrm{~mm}$ & $99.0-104.0 \mathrm{~mm}$ \\
\hline $1-\mathrm{L}$ vessel's wall thickness & Not specified & $2.3-3.7 \mathrm{~mm}$ \\
\hline $1-L$ flange o.d. & Not specified & $130.0-136.0 \mathrm{~mm}$ \\
\hline \multicolumn{3}{|l|}{ Paddle Specifications } \\
\hline Material of construction & $\begin{array}{l}\text { Shaft and blade are } 303 \text { (or } \\
\text { equivalent) stainless steel (SS) with } \\
\text { bottom of blade flush with shaft }\end{array}$ & $\begin{array}{l}\text { Machined } 316 \text { SS hollow shaft with an } \\
\text { embedded temperature sensor. } 316 \text { SS } \\
\text { threaded blade sealed by a Viton } 0 \text { ring }\end{array}$ \\
\hline Identification & Not specified & Serialized \\
\hline Shape of paddle and shaft & $\begin{array}{c}\text { As specified in Figure } 2 \text { of USP } \\
\text { General Chapter }\langle 711\rangle \text {, Dissolution }\end{array}$ & Conforms to USP \\
\hline Shaft length (without paddle) & Not specified & $454.0-464.0 \mathrm{~mm}$ \\
\hline Shaft o.d. & $9.4-10.1 \mathrm{~mm}$ & $9.47-9.55 \mathrm{~mm}$ \\
\hline Blade height & $18.5-19.5 \mathrm{~mm}$ & $18.6-19.4 \mathrm{~mm}$ \\
\hline Blade thickness & $3.0-5.0 \mathrm{~mm}$ & $3.2-4.8 \mathrm{~mm}$ \\
\hline Upper blade width & $74.0-75.0 \mathrm{~mm}$ & $74.0-75.0 \mathrm{~mm}$ \\
\hline Tip's radius of curvature & $1.2 \mathrm{~mm}( \pm 1.0 \mathrm{~mm})$ & $1.2 \mathrm{~mm}(-0.2 \mathrm{~mm}$ to $+0.8 \mathrm{~mm})$ \\
\hline Blade's width at bottom & $42.0 \mathrm{~mm}( \pm 1.0 \mathrm{~mm})$ & $42.0 \mathrm{~mm}( \pm 0.9 \mathrm{~mm})$ \\
\hline $\begin{array}{l}\text { Blade's radius of curvature (when } \\
\text { measured from center of shaft } \\
35.8 \mathrm{~mm} \text { from the blade's bottom) }\end{array}$ & $41.5 \mathrm{~mm}( \pm 1.0 \mathrm{~mm})$ & $41.5 \mathrm{~mm}( \pm 0.9 \mathrm{~mm})$ \\
\hline \multicolumn{3}{|l|}{ Vessel Covers } \\
\hline Material of construction & Not specified & Acrylic halves joined with acetel hinge \\
\hline \multirow[t]{2}{*}{ Design } & $\begin{array}{l}\text { Fitted cover with openings for } \\
\text { thermometer and specimen }\end{array}$ & $\begin{array}{l}\text { Hinged, fitted cover with one capped } \\
\text { opening on each half for sampling }\end{array}$ \\
\hline & withdrawal & \\
\hline o.d. and thickness & Not specified & $\begin{array}{c}18.0-124.0 \mathrm{~mm} \text { (o.d.) } \\
11.0-15.0 \mathrm{~mm} \text { (thickness) }\end{array}$ \\
\hline
\end{tabular}

receipt of corporate approval, the activities outlined in the protocol began. As the studies progressed, the details of the plan were updated to incorporate changes arising from experimental findings, scheduling, and priority conflicts. The approved plan required that, at a minimum, the critical components be determined to meet the USP tolerances before any system performance studies would be initiated. In addition, before any operational studies were to be conducted, the plan required that physical and position measurements of the sys- tem's key components be determined to meet the manufacturer's specifications and that the temperature accuracies of the system's reference probe and the seven temperature-sensing shafts be shown to be accurate in comparison with an appropriate NIST-traceable external temperature-measuring system.

The plan called for first sequentially determining room temperature, vessel dimensions, shaft and paddle dimensions, vessel cover dimensions, and the system's calibration probe (Cal. Probe) temperature reference unit's conformity to a
NIST-traceable, calibrated TempChek temperaturemeasurement system (Distek).

Then, the seven shafts were to be calibrated, the vessels installed, the paddle heights set, and the paddle centering, clearance, wobble, and rise determined. Next, the paddles' rotations were to be determined to conform to USP specifications as well as to the manufacturer's tighter acceptance criteria using an RPMChek, a NIST-traceable, high-resolution (0.1-rpm) tachometer (Distek). The next step was to study the heating of 
Table II: Dperational performance targets and tolerances.

\begin{tabular}{|c|c|c|}
\hline Item & uSP Targets and Tolerances & Vendor Targets and Tolerances \\
\hline Main unit vessel support plate's level & Implicitly level & $\begin{array}{c}\text { Bubble on standard } 25-\mathrm{mm} \text { or larger } \\
\text { diameter bubble level must be within } \\
\text { the level's centering circle }\end{array}$ \\
\hline Shaft runout & Not specified & $\leq 0.26 \mathrm{~mm}$ \\
\hline Installed blade runout & $\leq 0.5 \mathrm{~mm}$ & $\leq 0.5 \mathrm{~mm}$ \\
\hline $\begin{array}{l}\text { Installed shaft deviation from } \\
\text { vessel center line (centering) }\end{array}$ & $\leq 2.0 \mathrm{~mm}$ & $\leq 2.0 \mathrm{~mm}$ \\
\hline $\begin{array}{l}\text { Clearance between bottom of installed } \\
\text { paddle blade and the inside bottom of } \\
\text { its vessel (paddle not rotating) }\end{array}$ & $23.0-27.0 \mathrm{~mm}$ & $23.0-27.0 \mathrm{~mm}$ \\
\hline $\begin{array}{l}\text { Maximum upward displacement of } \\
\text { paddle when shaft is rotating }\end{array}$ & $\leq 0.5 \mathrm{~mm}$ & $\leq 0.5 \mathrm{~mm}$ \\
\hline Rotational speed control accuracy & $\pm 4 \%$ of target for $25-250 \mathrm{rpm}$ & $\begin{array}{l} \pm 1 \% \text { of target for } 25-49 \mathrm{rpm} \\
\pm 0.5 \% \text { of target for } 50-150 \mathrm{rpm} \\
\pm 0.3 \% \text { of target for } 151-250 \mathrm{rpm}\end{array}$ \\
\hline $\begin{array}{l}\text { Operating clearance between drive } \\
\text { unit and top of vessels when operating } \\
\text { (important for sampling access) }\end{array}$ & Not specified & At least $190.0 \mathrm{~mm}$ \\
\hline $\begin{array}{l}\text { Temperature of dissolution medium } \\
\text { when set at } 37.0^{\circ} \mathrm{C}\end{array}$ & $36.5-37.5^{\circ} \mathrm{C}$ & $36.65-37.35^{\circ} \mathrm{C}$ \\
\hline $\begin{array}{l}\text { Temperature difference between medium } \\
\text { in different vessels (vessels at } 37^{\circ} \mathrm{C} \text { ) }\end{array}$ & Not specified & $\begin{array}{c}\leq 0.4^{\circ} \mathrm{C} \\
\text { (paddles at } 25-250 \mathrm{rpm} \text { ) }\end{array}$ \\
\hline $\begin{array}{l}\text { Temperature homogeneity within a } \\
\text { filled } 1-\mathrm{L} \text { vessel ( } 1 \mathrm{~L} \text { of water and top, } \\
\text { middle, bottom, and shaft sensors used } \\
\text { to determine this) }\end{array}$ & Not specified & $\begin{array}{c}\leq 0.3^{\circ} \mathrm{C} \\
\text { (paddles at } 25-250 \mathrm{rpm} \text { ) }\end{array}$ \\
\hline $\begin{array}{c}\text { Time to heat } 1 \mathrm{~L} \text { of water from the lab's } \\
\text { ambient temperature }\left(\geq 20^{\circ} \mathrm{C}\right) \text { to } \\
37^{\circ} \mathrm{C} \text { within USP limits }\end{array}$ & Not specified & $\begin{array}{l}\leq 21 \mathrm{~min} \text { (paddles at } 25 \mathrm{rpm} \text { ) } \\
\leq 12 \mathrm{~min} \text { (paddles at } 250 \mathrm{rpm} \text { ) }\end{array}$ \\
\hline $\begin{array}{l}\text { Short-term (15-min) drift in temperature } \\
\qquad\left(\text { set }=37^{\circ} \mathrm{C}\right)\end{array}$ & Not specified & $\begin{array}{c}\leq 0.25{ }^{\circ} \mathrm{C} \\
\text { (paddles at } 25-250 \mathrm{rpm} \text { ) }\end{array}$ \\
\hline $\begin{array}{l}\text { Long-term (24-h) drift in temperature } \\
\qquad\left(\text { set }=37^{\circ} \mathrm{C}\right)\end{array}$ & Not specified & $\begin{array}{c}\leq 0.35{ }^{\circ} \mathrm{C} \\
\text { (paddles at } 25-250 \mathrm{rpm} \text { ) }\end{array}$ \\
\hline
\end{tabular}

1- $\mathrm{L}$ aliquots of water to $37^{\circ} \mathrm{C}$ as well as temperature stabilization while stirring at the limits (25 rpm and $250 \mathrm{rpm})$. The purpose of this step was to verify that the system met its initial heating and temperature stabilization requirements. When the preceding studies were successfully completed, tests were to be conducted addressing temperature gradient (top, middle, and bottom) and temperature fluctuation. The effect on temperature stability and set point of removing the vessel covers was also to be studied.

To complete the validation, short-term (15-min) and longterm (24-h) temperature and rpm conformity studies were to be conducted with the paddles rotating at $250 \mathrm{rpm}$. Following completion of the initial studies, the analysts decided to add a short-term (15-min) and longterm (24-h) temperature and rpm conformity study with the paddles rotating at $25 \mathrm{rpm}$. This was done to establish the effect of low-speed stirring on the temperature conformity of the vessel's contents to set point.

\section{EXPERIMENTS, RESUITS, AND FINDINGS}

The vessels to be used were identified and their suitability verified by measuring key dimensions. Their bottom hemisphericity was confirmed using the manufacturer's standard template. Next, the vessel covers' dimensions were confirmed to meet the manufacturer's specifications. Following this, the paddle shafts and their position in the system were identified and the shafts' diameters and certain key paddle dimensions were measured. In addition, suitable standard metal templates were used to confirm the radius of curvature of the blades and the blade tips.

Following the verification of the physical dimensions of the vessels, paddles, and vessel covers, the vessels were installed in their designated locations and 


\section{Bathless Dissolution.....ent}

the clearance of the paddles from the vessel bottoms was set. Next, the centering of the shafts in the vessels and the clearance between each paddle and the drive head were measured and found to meet specifications. Paddle centering and clearance were checked periodically to confirm conformance to specifications throughout the study.

In conjunction with per- forming the required physical measurements, the accuracy of the system's calibration probe was confirmed to give temperature values accurate within $0.03^{\circ} \mathrm{C}$ in the interval from $22^{\circ} \mathrm{C}$ to $40^{\circ} \mathrm{C}$. The differences observed between the calibration probe and the calibrated, NIST-traceable unit were $+0.03^{\circ} \mathrm{C}$ at $22.2^{\circ} \mathrm{C}$ and $-0.01^{\circ} \mathrm{C}$ at $40.0^{\circ} \mathrm{C}$. (The NIST-traceable unit's accuracy is such that its values are accurate to within $\pm 0.02^{\circ} \mathrm{C}$ in the range between 20 and $50^{\circ} \mathrm{C}$ ). The calibration probe was then used to perform a two-point calibration (at $\sim 20^{\circ} \mathrm{C}$ and $\sim 37^{\circ} \mathrm{C}$ ) of the seven temperature-sensing shafts using vessels filled with water stirred at $150 \mathrm{rpm}$ per the manufacturer's current calibration procedure. In addition, the proper operation of the safety interlock that disables rotation

\section{Notes}

1. In water bath-based systems, a major factor that limits the heating of the vessel's contents is the limited temperature gradient between the medium in the vessel and the water bath. The initial difference is typically on the order of $15^{\circ} \mathrm{C}$. In contrast, whereas the initial temperature gradient between the direct-heating jacket and its vessel is typically only a few degrees, this system is capable of rapidly increasing the jacket's temperature to the point that maximum gradient can be more than five times that generated by the water bath. Moreover, as the vessel's contents begin to warm, the system's controllers adjust the heat input based on the temperatures being fed back from the shaft probes.

2. When the medium is heated to its target temperature, stirring should be as rapid as possible to the point that air starts becoming entrained in the medium or, in cases in which the medium contains certain surfactants, the medium begins to foam. For water, $\geq 0.1 \mathrm{~N}$ aqueous hydrochloric acid, simulated gastric fluid without enzymes, and simulated intestinal fluid without enzymes, 150 rpm is a good compromise value. If the analyst is concerned about resaturating the medium with air before the start of the test period, he or she should consider using systems that dispense deaerated medium at the test temperature into the vessels. This is true because the medium, if in contact with air, rapidly equilibrates to saturation during any period of stirring and heating. This is the case partly because the solubility of air in the medium decreases as the medium is heated. In addition, the time to reach temperature equilibrium, even in an actively heated system such as the one used here, is at least $15 \mathrm{~min}$. Water bath-based systems typically require more than twice as long. Consequently, the medium will be close to saturation at the beginning of a valid test unless the medium has been degassed and preheated to the required temperature and is maintained in this state until just before dispensing.

3 . In actuality, the time for the system to equilibrate to a given temperature is a complex function of the initial fill volume (typically $500-1000 \mathrm{~mL}$ in a standard USP 1-L vessel), the initial fill volume's temperature, the stirring rate, and the system's set point. On the lower end, the set point is limited to the greater of $20^{\circ} \mathrm{C}$ or ambient $+5.0^{\circ} \mathrm{C}$ and, because of the system's design, to $45^{\circ} \mathrm{C}$ on the upper end.

3.1 As a general rule of thumb, the closer the temperature of the fill is to the set point, the shorter is the time required to equilibrate the contents to the set point temperature. It is important to prevent the heating process from raising the medium's temperature significantly above the set point because dissolution systems are not, because of cost and reliability considerations, designed to provide active cooling.

3.2 Up to a point (see Note 2), increasing the stirring speed (rpm) during the heat-up period will reduce the equilibration time.

3.3 Because the vessel jackets actually contain a lower heater designed to heat the region from the jacket's bottom to just below the $500-\mathrm{mL}$ level and an upper heater to heat the region from 500 $\mathrm{mL}$ to just below $900 \mathrm{~mL}$, the system uses the fill level to limit the heaters used in heat-up. To minimize the risk of damage to the vessels and the heater jackets, the system uses only the lower heater for fills up to $500 \mathrm{~mL}$. Both heaters are used for volumes between $500 \mathrm{~mL}$ and $1000 \mathrm{~mL}$.

3.4 Based on the initial fill's temperature, the system also selects an initial heating rate to minimize the risk of overheating the medium and periodically updates that rate based on the temperature measurements fed back by the shafts' sensors.

4. Should one wish to place a suitable small-thermal-mass, rapid-response temperature probe at a top position that is not biased by heat transfer effects occurring at the vessel's surface, it is recommended that it be placed so that its active region is just below the $900-\mathrm{mL}$ level for a 1-L fill, just at the $800-\mathrm{mL}$ level for a $900-\mathrm{mL}$ fill, or just at the 650 $\mathrm{mL}$ level for a $750-\mathrm{mL}$ fill. For $500-\mathrm{mL}$ studies, it is recommended that a suitable probe be positioned at the top and bottom because the region of the probe that must be immersed for an accurate reading remains unchanged. The two recommended levels are at $350-400 \mathrm{~mL}$ for the upper position and at $150-200$ $\mathrm{mL}$ for the lower position.

5. It is recommended that the system be installed in areas of low airflow. If it is installed where there is a significant airflow across the unit, such as near an HVAC register, then the unit should be shielded from this draft in order to operate within its design specifications. Although this is always an important issue, it is especially true for the user who chooses to operate the system without the covers installed. 
when the drive head is fully raised was also confirmed.

After centering and clearance verification, the shaft rpm, shaft wobble (at just above the blade), and paddle lift were measured and found to meet specifications. At this point, the experiments had established that the system was suitable for studying various aspects of the system's temperature performance. Vessel fill volume was fixed at $1 \mathrm{~L}$. Because the goal was to establish that the system performs within its stated temperature tolerances across the entire range of controlled stirring speeds, the temperature studies were performed at the lowest $(25 \mathrm{rpm})$ and at the highest $(250 \mathrm{rpm})$ stirring speed in the manufacturer's specified control range.

Though a variety of studies were performed, this article will present only the key results obtained. The bathless system uses heater jackets to directly heat and maintain the vessel's contents at a given temperature. Because each temperature-sensing stirring shaft is used to monitor temperature and to provide feedback to the vessel's heater-control circuitry, the medium's heating and temperature control are the crucial aspects of this system's performance that must be established.

The experiments discussed below are:

- initial heating

- divergence of the equilibrium temperature from the set point

- temperature uniformity within the medium in the vessel

- long-term limiting temperatures about the set point

Table III: Study schedule for initial heating and stabilization.

\begin{tabular}{|cccccc|}
\hline Day & $\begin{array}{c}\text { Stirring } \\
\text { Speed }(\mathrm{rpm})\end{array}$ & $\begin{array}{c}\text { Water Start } \\
\text { Temperature } \\
(8 \mathrm{C})\end{array}$ & $\begin{array}{c}\text { Analyst } \\
\text { Number }\end{array}$ & $\begin{array}{c}\text { Results } \\
\text { Presented } \\
\text { in Trial \# }\end{array}$ & Remarks \\
\hline 1 & 25 & 21.5 & 1 & B1 & \\
& 250 & 21.7 & 1 & A1 & \\
\hline 2 & 25 & 24.6 & 1 & D1 & \\
& 250 & 22.9 & 1 & C1 & Repeat of Day 1 \\
\hline 3 & 25 & 21.5 & 2 & B2 & \\
& 250 & 20.1 & 2 & E1 & \\
\hline
\end{tabular}

Table IV: Initial medium heating and medium stabilization studies.

\begin{tabular}{|c|c|c|c|c|c|c|}
\hline \multirow[b]{2}{*}{ Trial ID* } & \multicolumn{3}{|c|}{$\frac{\text { Paddles at } 250 \mathrm{rpm}}{\text { Time }(\mathrm{min}) \text { and Temperature }\left({ }^{\circ} \mathrm{C}\right)}$} & \multicolumn{3}{|c|}{$\frac{\text { Paddles at } 25 \mathrm{rpm}}{\text { Time }(\mathrm{min}) \text { and Temperature }\left({ }^{\circ} \mathrm{C}\right)}$} \\
\hline & A1 & C1 & E1 & B1 & D1 & B2 \\
\hline Start & O 21.7 & 022.9 & o 20.1 & O 21.5 & 024.6 & O 21.5 \\
\hline Met USP & 1236.9 & 937.1 & 1236.9 & 1837.1 & 1237.4 & 1537.0 \\
\hline Met Distek & 1236.9 & 937.1 & 1236.9 & 2136.9 & 1836.9 & 1736.9 \\
\hline Equilibrium & 1936.95 & 1736.96 & 1936.93 & 2536.94 & 2536.98 & 2336.94 \\
\hline Temp. & Avg. & 36.95 & & Avg. & 36.95 & \\
\hline
\end{tabular}

- the effect on the equilibrium set point when the vessel's covers are removed.

\section{INITIAL HEATING}

By not stating the initial temperature of the medium being dispensed, USP 23's General Chapter $<711>$, Dissolution, expects that the initial temperature of the medium being dispensed will be $\sim 25^{\circ} \mathrm{C}$ (USP 23, General Notices, p. 9). Therefore, the analyst is expected to dispense the appropriate volume of lab-temperature medium, cover the vessels to minimize evaporative losses that could affect result accuracy, and heat the vessel's contents to $37.0^{\circ} \mathrm{C}$ while stirring. Accordingly, a series of experiments was performed in which $1 \mathrm{~L}$ of water, at temperatures between $20^{\circ} \mathrm{C}$ and $25^{\circ} \mathrm{C}$, was placed in each of the vessels and allowed to equilibrate briefly. Then heating was initi- ated and system performance monitored. The stirring rate was varied because, outside of initial medium temperature and volume of fill, it has a significant effect on the time required for the system to stabilize within USP's allowed temperature range $\left(36.5-37.5^{\circ} \mathrm{C}\right)$. One-liter volumes were selected because they represent the vessel's maximum fill. Table III presents the experimental set that resulted, and Table IV summarizes the results. As the data clearly show, the stirring rate has a major effect on equilibration time both with respect to meeting USP's allowed range and to reaching a steady state. The 250-rpm tests showed that, depending on the initial temperature of the water used, it took from 9 to $12 \mathrm{~min}$ to reach USP's range, whereas at $25 \mathrm{rpm}$ it took $12-18 \mathrm{~min}$.

Further, though the times to reach near-steady-state temper- 


\section{Bathless Dissolution....continued}

atures varied from 11 to $12 \mathrm{~min}$ at $250 \mathrm{rpm}$, the corresponding times at $25 \mathrm{rpm}$ were from 17 to $21 \mathrm{~min}$. In addition, the data also indicated that the control band (the range of temperatures about the average values), though small $\left(<0.1^{\circ} \mathrm{C}\right)$, was at least $50 \%$ wider when the stirring rate was $25 \mathrm{rpm}$ than it was when the stirring rate was 250 $\mathrm{rpm}$. These findings indicate that it is best to keep the initial temperature of the bulk medium as near $25^{\circ} \mathrm{C}$ as is feasible to minimize heat-up times. By comparison, the times to heat the contents of a borosilicate-glass vessel under the same conditions using typical water bath-based systems are more than twice the times reported here (see also sidebar, Notes 1-4).

Finally, as a result of the algorithms used in the system's software and the hardware design, the equilibrium temperatures observed for a $37.0^{\circ} \mathrm{C}$ set point converged on $\sim 36.95 \pm 0.03^{\circ} \mathrm{C}$ in all six trials (see Table IV).

\section{DIVERGENGE OF THE EOUIIBRIUM TEMPERATURE FROM THE SET POINT}

A fundamental problem facing the designers of near-roomtemperature temperaturecontrol systems that provide active heating but rely on ambient air for cooling is that temperature overshoot must be minimized because ambient air is a poor coolant. This is one reason that the designers of such systems typically specify the system's lower control limit as ambient plus $5^{\circ} \mathrm{C}$. The dissolution system described in this article belongs to this class of temperature-control systems.

As the preceding and the following data indicate, though the system's set point was $37.0^{\circ} \mathrm{C}$, the temperatures reported by the shafts' calibrated probes, accurate to within $0.02^{\circ} \mathrm{C}$, apparently converged to $36.95^{\circ} \mathrm{C}$. Considering the fact that, to minimize customer cost, this system has no active cooling components, this small divergence is within the $\pm 0.1^{\circ} \mathrm{C}$ design tolerance allowed. Moreover, this result is well within the set point control tolerance required by USP $\left( \pm 0.5^{\circ} \mathrm{C}\right)$ and the manufacturer's tighter $\pm 0.35^{\circ} \mathrm{C}$ tolerance.

\section{TEMPERATURE UNIFORMITY OF THE MEOIUM IN THE VESSEL}

Vessel temperature uniformity is one of the areas that must be addressed in the performance validation of any dissolution system. USP does not address this issue, and the authors found no published factual information in this area. As before, studies were conducted at the limits of the stirrer's controlled operating range both to cover the system's controlled stirring range and to provide the maximum difference so that experiments would have the best chance of identifying and estimating even a small stirrerrpm effect that otherwise might be buried in the noise.

After several preliminary studies, definitive studies were carried out (see Table V) using an accurate $\left( \pm 0.02^{\circ} \mathrm{C}\right.$ in the region from 20 to $50^{\circ} \mathrm{C}$ ), calibrated, small-volume, smallthermal-mass temperature probe and measurement system to study the temperature in each vessel at the $900-\mathrm{mL}, 500-$ $\mathrm{mL}$, and bottom levels in the vessel. The probe was inserted through the vessel's cover and positioned. Then, at approximately 2 -min intervals, triplicate readings were taken at each level and recorded. Only the last two readings were used in the determination of local temperature and temperature variability. The data from these two studies indicated the presence of small temperature gradients within the vessel.

Moreover, as expected, the temperature gradient formed when the $1-\mathrm{L}$ water aliquots were stirred at $25 \mathrm{rpm}$ was more noticeable and slightly larger than the gradient formed when the water was stirred at $250 \mathrm{rpm}$. Although the gradient between the bottom and the 500-mL level was buried in the experimental noise at $250 \mathrm{rpm}$ (but was estimated at $\pm 0.05^{\circ} \mathrm{C}$ ), its magnitude had increased to the point that it was approximately the same level as the system's apparent between-vessel variability in the 25 -rpm test. However, all measured values in the region between the bottom and the 500$\mathrm{mL}$ level were within the manufacturer's specifications. Even at $25 \mathrm{rpm}$, the divergences between the $500-\mathrm{mL}$ level and the bottom were within $0.2^{\circ} \mathrm{C}$ of the system's set point. Based on the findings from these studies, the uniformity of the zone from the middle of the vessel downward, where most of the initial dosage unit disintegration and initial dissolution take place, was established to be within the manufacturer's tighter tolerances.

However, the data clearly show that, as one might expect, the upper layer of the vessel, as measured at the $900-\mathrm{mL}$ level, 
Table V: 25-rpm and 250-rpm covered-vessel temperature uniformity.

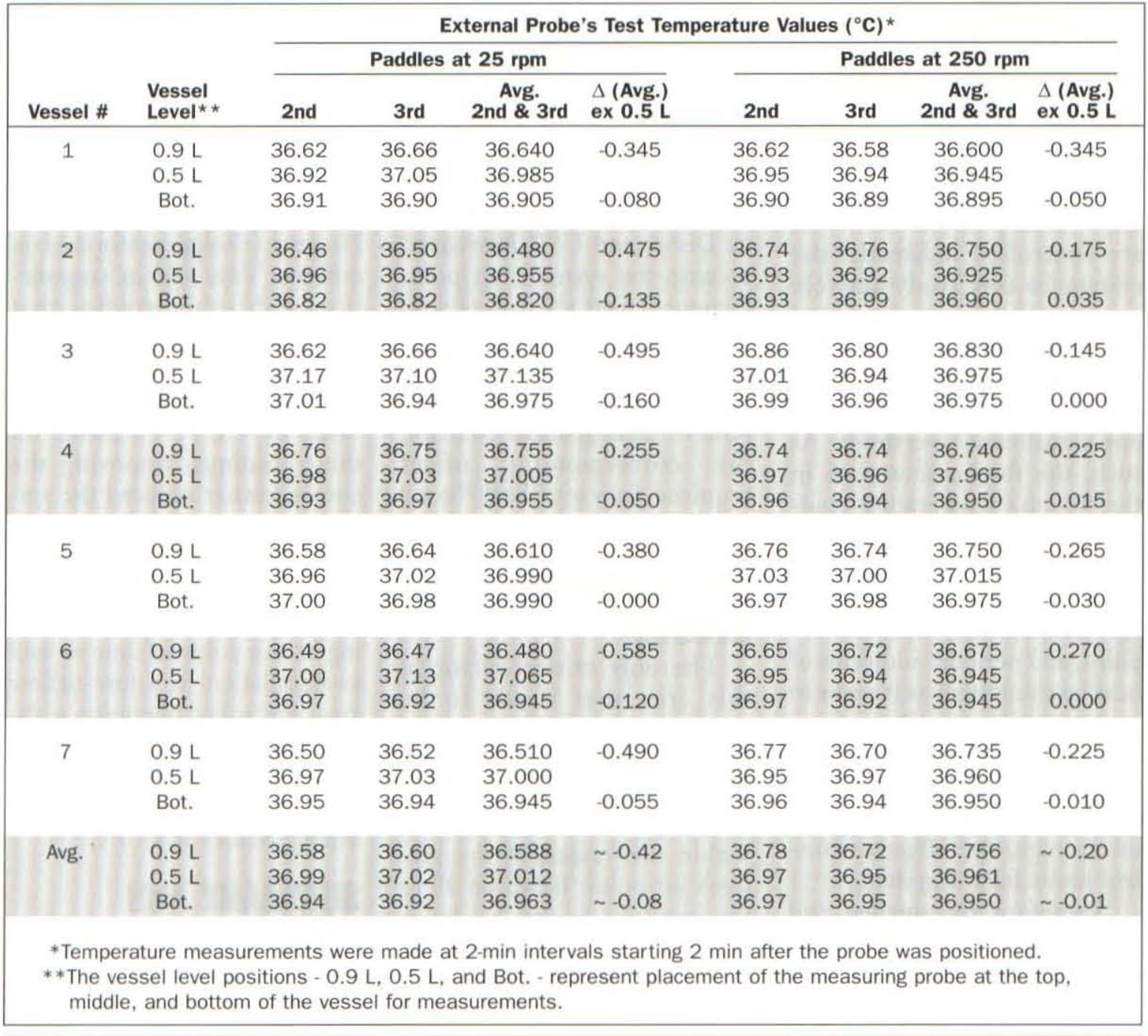

was slightly cooler than the bulk of the vessel's contents. At 250 rpm, the differences were all within both the manufacturer's and USP's ranges. At $25 \mathrm{rpm}$, the values still met USP's limit $\left(36.5^{\circ} \mathrm{C}\right.$ to $\left.37.5^{\circ} \mathrm{C}\right)$ because the lowest equilibrium values observed were, within experimental uncertainty, $36.5^{\circ} \mathrm{C}$. Moreover, given this result and the fact that the system converges to equilibrium temperature values within $\pm 0.05^{\circ} \mathrm{C}$ of the set point, one need only adjust the system's set point upward to $37.2^{\circ} \mathrm{C}$ to ensure that the temperature at the $900-\mathrm{mL}$ level is within USP's allowed $36.5-37.5^{\circ} \mathrm{C}$ range when stirring at speeds close to $25 \mathrm{rpm}$.

Based on the data generated in this study and because the medium is continuously stirred, the dissolution of a drug unit located in the bottom of the vessel would have been taking place, on average, at $36.95^{\circ} \mathrm{C}$. Furthermore, USP specifies an average temperature as opposed to a uniformity specification. Given this fact and the absence of other published data in this regard, the uniformity in each vessel serves only to establish this system's performance capabilities. Finally, the lack of a significant gradient, even when stirring at $25 \mathrm{rpm}$, between the $500-\mathrm{mL}$ level and the bottom clearly established that one need not apply heat to all of the vessel's surfaces to establish a uniform, controlled temperature in the vessel's contents, at least not for paddle speeds at or above $25 \mathrm{rpm}$. 


\section{Bathless Dissolution....continued}

\section{LONG-IERM TEMPERATURE FLUCTUATION ABOUT THE SET POINT}

Unlike water bath-based systems, in which the temperatures of the vessel's contents are controlled indirectly, the system in this study actively and continually monitors and seeks to control the temperature in the vessels as close to the set point as possible without significant overshoot. As such, the fluctuations seen in the system's temperature readouts are a combination of various random errors in the system's components, drifts in the temperature from the set point, and periodic additions of heat by the system as it seeks to maintain each vessel's contents at the set point. Thus, the range of values observed over time for this system represent, on average, the effective control limits for the system.

Therefore, the smallest and the largest temperature values observed in the data from the 24-h temperature-change monitoring studies served to define the long-term control limit ranges. As in the preceding studies, the midrange values were, within experimental error, all the same: $\geq 36.9^{\circ} \mathrm{C}$ $\left(36.95 \pm 0.03^{\circ} \mathrm{C}\right)$. In addition, at $250 \mathrm{rpm}$ the set point control range, as defined by the lowest and the highest values seen in these studies, was $36.96 \pm$ $0.11^{\circ} \mathrm{C}$. In the 25 -rpm study, as expected, the control range was larger because of lower rates of heat transfer and mixing. Based on the data from the $25-\mathrm{rpm}$ study, the control range for the system was $36.97 \pm 0.14^{\circ} \mathrm{C}$. In both cases, as in all of the other studies, a set point of $37.0^{\circ} \mathrm{C}$ generated an effective mean temperature of $\sim 36.95^{\circ} \mathrm{C}$. Thus, setting a $37.0^{\circ} \mathrm{C}$ set point resulted in attaining an average vessel content temperature that is well within the limits allowed by Distek and USP. Moreover, because the system's set point increment is $0.1^{\circ} \mathrm{C}$, users who wish to have the temperature of $\geq 37.0^{\circ} \mathrm{C}$ need only increase the system's set point by $0.1^{\circ} \mathrm{C}$ to achieve their goal. In contrast, the corresponding offset required in water bath-based dissolution systems is $\sim 0.5^{\circ} \mathrm{C}$.

\section{GOVER REMOVAL STUDIES}

The only critical factor in this area that needs to be resolved is the effect, if any, that removal of the covers has on the system's ability to maintain the temperature of the medium within the vessels at the system's set point. Based on all of the previous results, we know that the system's heating circuitry will attempt to compensate for the increased heat loss caused by removing the covers. The data obtained indicated that the system compensated for the removal of the covers in a manner that left the mean shaft temperature values close to their covered value equivalents. The test readings taken near the water's surface in the vessels showed no evidence of a significant change in the temperature in the upper layer.

Based on this study - and ignoring the errors in volume and the noncompliance with USP's expectation that are introduced by removal of the covers - the effect of operating without covers was small enough in this installation that the system continued to maintain the average temperature of the medium, as measured by the shaft probes, within both USP's and the manufacturer's tolerances (see sidebar, Note 5). However, though performed on different days and in conjunction with other studies that indicated that the system's control mean was $\sim 36.95^{\circ} \mathrm{C}$, both of these studies found a mean value of $\sim 36.91^{\circ} \mathrm{C}$. Based on these findings, removing the covers further reduced the system's control point by $\sim 0.04^{\circ} \mathrm{C}$ to $\sim 36.91^{\circ} \mathrm{C}$. Thus, in addition to requiring a reliable method to measure the volume remaining at any point in time as well as installation in a low-airflow area, controlled operation without covers would require at least a $0.1^{\circ} \mathrm{C}$ increase in the set point to keep the measured average values at $37.0^{\circ} \mathrm{C}$.

\section{SUMMARY AND CONCIUSION}

Based on the results obtained for both the cases reported in this discussion and other performance validation studies done at the same time, the results obtained have documented the system's performance and established that the system meets USP's and the manufacturer's specifications. This compliance has been demonstrated when the system was operated at $37.0^{\circ} \mathrm{C}$ with 1 $\mathrm{L}$ of water in each vessel and with the appropriate paddles, covered vessels, and rates of rotation at $25 \mathrm{rpm}$ and 250 $\mathrm{rpm}$. In addition to establishing the system's conformance to

See Bathless... continued page 22 


\section{Product News}

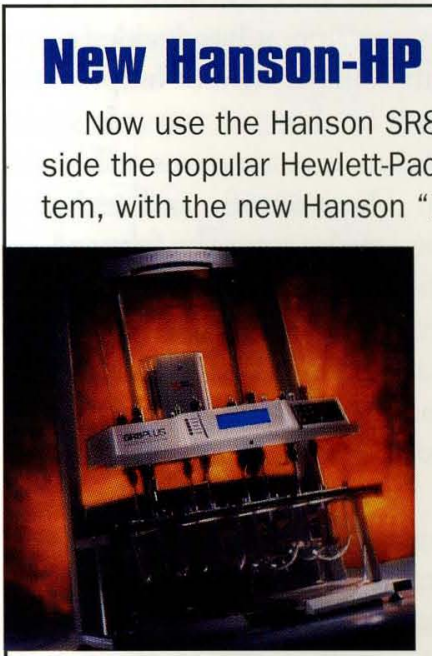

\section{Dissolution Interface}

8-Plus dissolution test station along"Priver." Tested and approved by Hewlett-Packard, the Hanson SR8Plus with HP Driver is fully functional with the HP 8453 diode array dissolution test system. The Hanson HP Driver is provided in diskette form (along with cable connector to COM port), and is easily installed in the PC. This programming interface allows for direct communications between the SR8Plus dissolution test station and the HP 8453 UV detector and computer with HP dissolution software. As well, convenient HP sample probe kits provide easy connection to the HP autosampler.

For additional information contact:

Hanson Research Corp.

9810 Variel Avenue

Chatsworth, CA 91311

(800)821-8165 (818)882-7266 Fax (818)882-9470

Website: www.hansonresearch.com

Bathless...continued from page 14

USP's requirements for controlled operation as well as conformance to all of the manufacturer's pertinent specifications, these studies have established the system's characteristics with respect to temperature uniformity, control point precision and accuracy, initial heating time, set point control limits, and cover removal. Appropriate studies at $25 \mathrm{rpm}$ and $250 \mathrm{rpm}$ have generated data that establish satisfactory performance of the system.

\section{References}

1. General Chapter <711> Dissolution, Apparatus Suitability Test, USP 23 (United States Pharmacopeial Convention, Rockville, MD), p. 1792.

Reprinted courtesy of Pharmaceutical Technology, An Advanstar Publication. Reference Pharmaceutical Technology 1998. Analytical Validation Issue for original publication.

\section{Dissolution Diseussion Group}

The Dissolution Discussion Group (DDG) allows fellow analysts from around the world to convene in an open forum, free of regulatory encumbrances to tap into resources, share

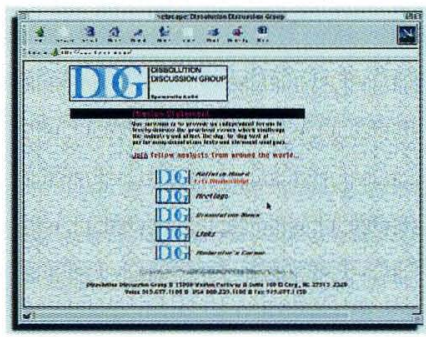
ideas, and encourage problem solving with regard to dissolution testing. Registration is free. Simply visit the DDG Web site at:

http://www.dissolution.com. Then access the site frequently to engage in real time discussions about dissolution questions, suggestions and techniques. The site includes a bulletin board for anonymous postings of challenges confronting dissolution analysts, as well as announcements for future DDG meetings and updates from previous meetings.

\section{OA II Station. Calibration. Verifiteation. Documentation.}

VanKel Technology Group's new QA II Station for calibrating dissolution testers was designed specifically to include the measurement of vibration in four parameters: acceleration, frequency, velocity and displacement in addition to checking standard parameters such as shaft wobble, spindle speed, etc. A complete hard-copy printout from the

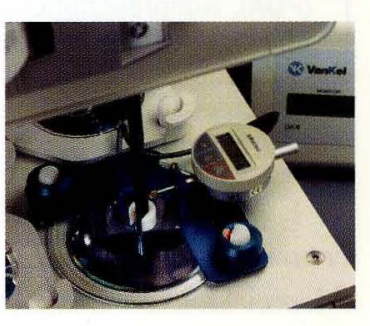
station's dot matrix printer provides the test results - including the vibration measurements in the X-Y-Z axes. The test data can also be downloaded to a PC via the built-in RS 232 interface. The unit has a non-volatile memory and an information capacity for up to 30 testers.

For more information call 1-800-229-1108. 